\title{
Optimal Operating Parameters of 100MW Delta IV Ughelli Gas Turbine Power Plant Unit
}

\author{
Obodeh Otunuya ${ }^{1}$, Ugwuoke Philip Emeka ${ }^{2}$ \\ ${ }^{1}$ Department of Mechanical Engineering, Ambrose Alli University, Ekpoma, Nigeria \\ ${ }^{2}$ Department of Mechanical Engineering, Petroleum Training Institute, Effurun, Nigeria
}

Email address:

engobodeh@yahoo.com (O. Otunuya),ugwuokeemeka@gmail.com (U. P. Emeka)

\section{To cite this article:}

Obodeh Otunuya, Ugwuoke Philip Emeka. Optimal Operating Parameters of 100MW Delta IV Ughelli Gas Turbine Power Plant Unit. International Journal of Energy and Power Engineering. Vol. 6, No. 5, 2017, pp. 68-74. doi: 10.11648/j.ijepe.20170605.11

Received: August 16, 2017; Accepted: August 28, 2017; Published: November 3, 2017

\begin{abstract}
The possibility of improving the overall efficiency of 100MW Delta IV Ughelli gas turbine power plant unit is presented. The study used Non-Dominated Sorting Genetic Algorithm (NSGA) to minimize the exergy destruction by optimally adjusting the operating parameters (decision variables). The adjusted operating variables were compressor pressure ratio $r_{\mathrm{p}}$, compressor isentropic efficiency $\eta_{\mathrm{ic}}$, turbine isentropic efficiency $\eta_{\text {it }}$, turbine inlet temperature $\mathrm{T}_{3}$, inlet flow rate of air $\dot{m}_{\mathrm{a}}$ and mass flow rate of fuel $\dot{m}_{f}$. The ambient temperature and pressure were held constant at $303 \mathrm{~K}$ and 1.013 bar respectively because of location limitations. The optimization code was written in MATLAB programming language. The decision variables (constraints) were obtained randomly within the admissible range. The optimal values of the decision variables were obtained by minimizing the objective function (total exergy destruction). The choice of 300 generations was to enable the full utilization of the search space without putting strain on the computation time and complexity. The determined optimum values of the operating variables were $\mathrm{r}_{\mathrm{p}}=12.41, \eta_{\mathrm{ic}}=86.40 \%, \eta_{\mathrm{it}}=89.12 \%, \mathrm{~T}_{3}=1,486.36 \mathrm{~K} \dot{m}_{\mathrm{a}}=355.82 \mathrm{~kg} / \mathrm{s}$ and $\dot{m}_{\mathrm{f}}=8.62 \mathrm{~kg} / \mathrm{s}$. The obtained optimal values of $\mathrm{r}_{\mathrm{p}}, \eta_{\mathrm{ic}}, \eta_{\text {it }}$ and $\mathrm{T}_{3}$ were higher than their base values while that for $\dot{m}_{\mathrm{a}}$ and $\dot{m}_{\mathrm{f}}$ were less. Increased $\mathrm{r}_{\mathrm{p}}$ brings about higher thermal efficiency while increased $\eta_{\text {ic }}$ guarantees less exergy destruction in the compressor. Increased $\eta_{\text {ic }}$ and $\mathrm{T}_{3}$ are crucial in decreasing the exergy destruction in the combustion chamber and in reducing the cycle fuel consumption. Reduced $\dot{m}_{\mathrm{a}}$ and $\dot{m}_{\mathrm{f}}$ play vital roles in the reduction of the total exergy destruction. They reduction also result in less emissions from the plant thereby decreasing the gas turbine's negative impacts on the environment. Suggested coatings of compressor blades will lead to increased compressor efficiency whereas thermal barrier coatings of the hot sections of the plant will increase the lifespan of the parts at the designed firing temperature. Thermal barrier coatings also allow increased firing temperature while still maintaining the original designed lifespan.
\end{abstract}

Keywords: Optimization, Genetic Algorithm, Exergy Destruction, Thermal Efficiency

\section{Introduction}

Restructured and liberalized power sectors promote increased competition among players in the sector. Deregulated energy markets require existing power plants to improve their performance in order to attain high thermal efficiency and reliability, so as to operate at low generation cost. To reduce cost during the entire operation time of a plant, selection of optimal operating parameters in different load situations is of an utmost importance [1-3]. Optimal operating parameters will bring about reduction of irreversibilities, which is a vital condition for better plant performance [4-5].

Exergy analysis has been found as a useful method in design, evaluation, optimization and improvement of thermal power plants [1], [6-8], [5]. It has proven to be a powerful tool in the thermodynamics analysis of exergy systems [910]. Exergy analysis gives a quantitative and illustrative description of the convertibility of different energy forms. It asserts the fact that energy cannot be destroyed but the quality can be degraded such that it reduces its ability to do useful work [10]. As it is known, the processes in all real energy conversion systems are irreversible and a part of the exergy supplied to the total system is destroyed. The concept of exergy is very useful for the identification of losses and 
irreversibility in the system by providing a more detailed tracking mechanism for energy usage [10]. The real inefficiencies of a system are exergy destruction occurring within the system boundaries and exergy losses, which are exergy transferred out of the system that are not further used in the overall system.

In this study, Genetic Algorithm (GA) was applied to minimize the exergy destruction by optimally adjusting the operating parameters. The workability of GA is based on Darwinian's theory of survival of the fittest. They were originally designed as simulators [11] but have proven to be a robust optimization technique [12-13]. The term robust denotes the ability of GA in finding the global optimum or a near-optimum for any optimization problem. GA may contain a chromosome, a gene, set of population, mutation and selection.

Genetic algorithm uses two operators to generate new solutions from existing ones: crossover and mutation. The crossover operator is the most important operator of GA. In crossover, two chromosomes called parents are combined to form new chromosomes, called off-springs. The parents are selected among the existing chromosomes in the population with preference to fitness. This enables the off-springs to inherit good genes making them better than their parents. By iteratively applying the crossover operator, genes of good chromosomes are expected to appear more frequently in the population, eventually leading to convergence to an overall good solution. The mutation operator introduces random changes into the characteristics of the chromosomes. The aim of mutation is to introduce new genetic material into existing individual; that is, to add diversity to the genetic characteristics of the population. The population which is created randomly at the onset is called initial population. The size of this population may vary from several tens of chromosomes (strings) to several thousands. The criterion applied in determining an upper bound for the size of population is that further increase does not result in improvement of near-optimal solution. The upper bound for each problem is determined after some test runs. For most applications, the best population size lies within the limits of $100-1,000$ strings [12-13]. On the basis of the optimality (measure of goodness) value, an objective function value or fitness value is assigned to each string. This fitness usually set as the amount of optimality of each string in the population divided by the average population optimality. Effort is always made to ensure that the fitness value is a positive number [12]. It is possible that a certain string does not reflect an allowable condition. For such a case, the fitness of the string is penalized with a very low value, indicting in such a way to the GA that it is not a good string. Similarly, other constraints may be implemented in the GA. The "operators", which are kinds of population transformation devises, are applied to the population. As a result of these operators, a new population is created, that will hopefully consist most optimal strings. The old population is replaced by new one. A predefined stopping criterion, usually maximum number of generations to be performed by the GA is checked. If the criterion is not satisfied, a new generation is started, otherwise, the GA terminates.

The objective of this study is to evaluate the possibility of improving the overall thermal efficiency of the $100 \mathrm{MW}$ gas turbine power plant unit using GA to minimize the exergy destruction by optimally adjusting the operating parameters. The parameters are: compressor pressure ratio, compressor isentropic efficiency, turbine isentropic efficiency and turbine inlet temperature. Exergy can be divided into four distinct components. The two important ones are physical exergy and chemical exergy. In this study, the other components, that is, kinetic exergy and potential exergy were assumed negligible as elevation and speed have negligible changes in the system under investigation.

\section{Materials and Method}

The data used for this study were measured values recorded in the station's operation logbook for the period of January 2005 to December 2014 [14]. Parameters considered during the data collection were the pressures, temperatures and mass flow rates at various points. In the analysis of the data, daily, monthly and yearly mean values of the parameters were computed using MS Excel worksheet. Figure 1 shows the simplified schematic diagram of the power plant, depicting relevant components while Figure 2 is the T-s diagram.

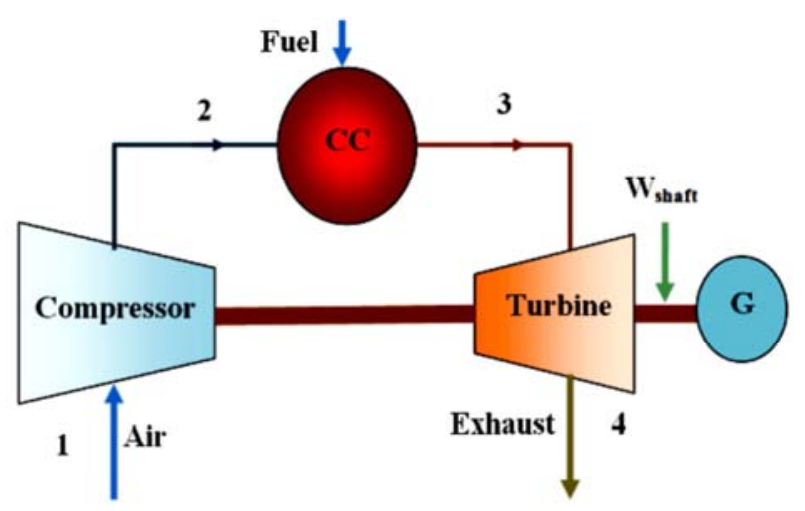

Figure 1. Schematic diagram of an open gas turbine.

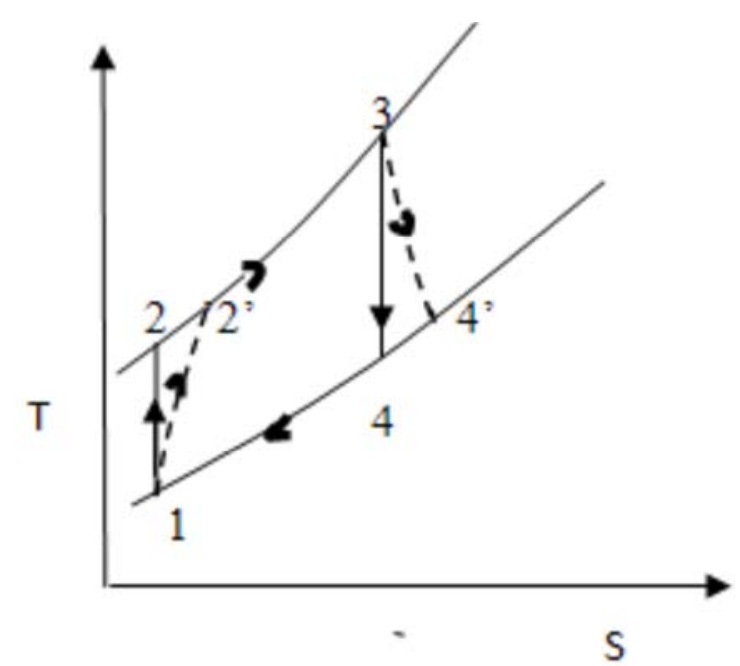

Figure 2. T-S Diagram. 
The plant's thermodynamics data are shown in Table 1. The mean daily temperature of the region hovers around $27^{\circ} \mathrm{C}$ all the year round. The minimum and maximum temperatures are $20^{\circ} \mathrm{C}$ and $40^{\circ} \mathrm{C}$ respectively [15]. Hence, in this study, $30^{\circ} \mathrm{C}$ was used as the mean ambient temperature and $1.013 \mathrm{bar}$ as its pressure.

Table 1. Thermodynamics data for $100 \mathrm{MW}$ gas turbine plant unit.

\begin{tabular}{ll}
\hline Ambient temperature, $T_{1}$ & $=303 \mathrm{~K}$ \\
Compressor outlet temperature, $T_{2}$ & $=619.4 \mathrm{~K}$ \\
Turbine inlet temperature, $T_{3}$ & $=1,324.74 \mathrm{~K}$ \\
Turbine outlet temperature, $T_{4}$ & $=805.07 \mathrm{~K}$ \\
Compressor inlet pressure, $p_{1}$ & $=1.013 \mathrm{bar}$ \\
Compressor outlet pressure, $p_{2}$ & $=10.84 \mathrm{bar}$ \\
Compressor pressure ratio, $r_{p}$ i.e. $\frac{p_{2}}{p_{1}}$ & $=10.70$ \\
Compressor isentropic efficiency, $\eta_{i c}$ & $=82 \%$ \\
Turbine isentropic efficiency, $\eta_{i t}$ & $=85 \%$ \\
Mass flow rate of fuel, $\dot{m}_{f}$ & $=9.13 \mathrm{~kg} / \mathrm{s}$ \\
Inlet mass flow rate of air, $\dot{m}_{a}$ & $=427 \mathrm{~kg} / \mathrm{s}$ \\
Power output, $\dot{W}_{\text {net }}$ & $=93.42 \mathrm{MW}$ \\
Lower heating value of fuel, $Q_{v}$ & $=46,778 \mathrm{~kJ} / \mathrm{kg}$ \\
\hline
\end{tabular}

In analysis of the plant, the cycle was assumed to operate at steady state with no stray heat transfer from one component to its surroundings and negligible kinetic and potential energy effects. For a control volume, an exergy balance equation is expressed as

$$
\sum \dot{W}=\sum\left(1-\frac{T_{O}}{T}\right) \dot{Q}+\sum \dot{\Psi}_{\text {in }}-\sum \dot{\Psi}_{\text {out }}-\sum \dot{\Psi}_{D}
$$

where

$\sum \dot{W}=$ sum of ideal work; $T_{o}=$ reference temperature; $T$ = temperature of the system; $\sum \dot{Q}=$ sum of heat supplied; $\sum \dot{\Psi}_{\text {in }}=$ sum of exergy inflow; $\sum \dot{\Psi}_{\text {out }}=$ sum of exergy outflow; $\sum \dot{\Psi}_{D}=$ sum of exergy destroyed in the system due to irreversibility.

where

$$
\begin{aligned}
& \dot{\Psi}=\dot{m}\left[C_{p}{ }^{h}\left(T-T_{o}\right)-T_{o}\left(s-s_{o}\right)\right] \\
& s-s_{o}=C_{p}{ }^{s} \ln \left(\frac{T}{T_{o}}\right)-R \ln \left(\frac{p}{p_{o}}\right)
\end{aligned}
$$

$\dot{m}$ is mass flow rate; $s$ is specific entropy; $C_{p}{ }^{h}$ and $C_{p}{ }^{s}$ are mean molar isobaric heat capacity for evaluating enthalpy and entropy respectively; $p$ is pressure of the system; $p_{o}$ is reference pressure and $R$ is characteristic gas constant.

Exergy destructions of system components are formulated as follows:
For the compressor, we have

$$
\dot{\Psi}_{D, 1}=\dot{W}_{C}-\left(\dot{\Psi}_{2}-\dot{\Psi}_{1}\right)
$$

where power input to the compressor, $\dot{W}_{C}$ is given by

$$
\dot{W}_{C}=\dot{m}_{a} C p_{a}{ }^{h}\left(T_{2}-T_{1}\right)
$$

$\dot{m}_{a}$ is mass flow rate of air; $T_{1}$ and $T_{2}$ are compressor inlet and outlet temperature respectively. By [3]:

$$
C_{p_{a}}(T)=1.04841-\frac{3.8371 T}{10^{4}}+\frac{9.4537 T^{2}}{10^{7}}-\frac{5.49031 T^{3}}{10^{10}}+\frac{7.9298 T^{4}}{10^{14}}
$$

For the combustion chamber, we have

$$
\dot{\Psi}_{D, 2}=\dot{\Psi}_{f}-\left(\dot{\Psi}_{3}-\dot{\Psi}_{2}\right)
$$

where $\dot{\Psi}_{f}$ is the chemical exergy rate of the fuel.

An approximate formula for specific chemical exergy of the fuel, $\psi_{f}$ of gaseous hydrocarbon fuels is [16], [8]:

$$
\frac{\psi_{f}}{Q_{v}}=1.033+0.0169 \frac{b}{a}-\frac{0.0698}{a}
$$

where $b=77.647$ and $a=11.933$ for methane, hence

$$
\psi_{f} \approx 1.06 Q_{v}
$$

But

$$
\dot{\Psi}_{f}=\dot{m}_{f} \psi_{f}=1.06 \dot{m}_{f} Q_{v}
$$

For the turbine, we have

$$
\dot{\Psi}_{D, 3}=\left(\dot{\Psi}_{3}-\dot{\Psi}_{4}\right)-\dot{W}_{t}
$$

where turbine power output, $\dot{W}_{t}$ is given by

$$
\dot{W}_{t}=\left(\dot{m}_{a}+\dot{m}_{f}\right) C_{p_{g}}{ }^{h}\left(T_{3}-T_{4}\right)
$$

$T_{3}$ and $T_{4}$ are turbine inlet and outlet temperature respectively. And as indicted by [3]:

$$
C_{p_{g}}(T)=0.991615+\frac{6.99703 T}{10^{5}}+\frac{2.7129 T^{2}}{10^{7}}-\frac{1.2244 T^{3}}{10^{10}}
$$

The total exergy destruction can be written as

$$
\sum \dot{\Psi}_{D}=\sum_{k}^{3} \dot{\Psi}_{D, k}
$$

In order to maximize the overall efficiency of the system, exergy destruction should be minimized. The objective function to be minimized is given by equation (11) subject to 
the constraints given in Table 2 in conjunction with equations (14) and (18).

Table 2. Optimization constraints and their rational.

\begin{tabular}{ll}
\hline Constraint & Reason \\
\hline $6 \leq r_{p} \leq 16$ & Commercial availability \\
$600 \mathrm{~K} \leq T_{2} \leq 900 \mathrm{~K}$ & Material limitation \\
$1,200 \mathrm{~K} \leq T_{3} \leq 1,600 \mathrm{~K}$ & Material limitation \\
$0.7 \leq \eta_{i c} \leq 0.9$ & Commercial availability \\
$0.7 \leq \eta_{i t} \leq 0.92$ & Commercial availability \\
$300 \mathrm{~kg} / \mathrm{s} \leq \dot{m}_{a} \leq 450 \mathrm{~kg} / \mathrm{s}$ & Commercial availability \\
$7.5 \mathrm{~kg} / \mathrm{s} \leq \dot{m}_{f} \leq 9.5 \mathrm{~kg} / \mathrm{s}$ & Commercial availability \\
\hline
\end{tabular}

Using Figure 2, we obtained

Compressor isentropic efficiency,

$$
\eta_{i c}=\frac{T_{1}-T_{2^{\prime}}}{T_{1}-T_{2}}
$$

But

$$
\frac{T_{2^{\prime}}}{T_{1}}=\left(\frac{p_{2}}{p_{1}}\right)^{\frac{\gamma-1}{\gamma}} \Rightarrow T_{2^{\prime}}=T_{1} r_{p}^{\frac{\gamma-1}{\gamma}}
$$

Combining equations (12) and (13), after simplifying, we have

$$
\eta_{i c}=\frac{1-r_{p}^{\frac{\gamma-1}{\gamma}}}{1-\frac{T_{2}}{T_{1}}}
$$

Turbine isentropic efficiency,

$$
\eta_{i t}=\frac{T_{3}-T_{4}}{T_{3}-T_{4^{\prime}}}
$$

But

$$
\frac{T_{3}}{T_{4^{\prime}}}=r_{p}^{\frac{\gamma-1}{\gamma}} \Rightarrow T_{4^{\prime}}=\frac{T_{3}}{r_{p}^{\frac{\gamma-1}{\gamma}}}
$$

Comparing equations (15) and (16) yields

$$
\eta_{i t}=\frac{\left(1-\frac{T_{4}}{T_{3}}\right)}{1-r_{p}^{\frac{1-\gamma}{\gamma}}}
$$

For ease of computer programming, equation (17) can be written as

$$
\eta_{i t}=\frac{r_{p}^{\frac{\gamma-1}{\gamma}}\left(1-\frac{T_{4}}{T_{3}}\right)}{r_{p}^{\frac{\gamma-1}{\gamma}}-1}
$$

The stopping conditions used for solving the optimization problem are the maximum number of generations and cumulative function tolerance, which are shown in Table 3.

Table 3. Stop criteria for the optimization algorithm.

\begin{tabular}{ll}
\hline Stop criterion & Value \\
\hline Number of generation & 300 \\
Function tolerance & $1 \times 10^{-7}$ \\
\hline
\end{tabular}

\section{Genetic Algorithm Optimization}

The optimization is done using Non-Dominated Sorting Genetic Algorithm (NSGA) proposed by [17]. The algorithm eliminates higher computational complexity, lack of elitism and the requirement for specifying sharing parameter. The developed GA code selects the decision variables in such a way to decrease the objective function. The flowchart of the algorithm is shown in Figure 3. The optimization code was written in MATLAB programming language. The decision variables were generated randomly within the admissible range (Table 3 ). The optimal values of the decision variables (constraints) were obtained by minimizing the objective function.

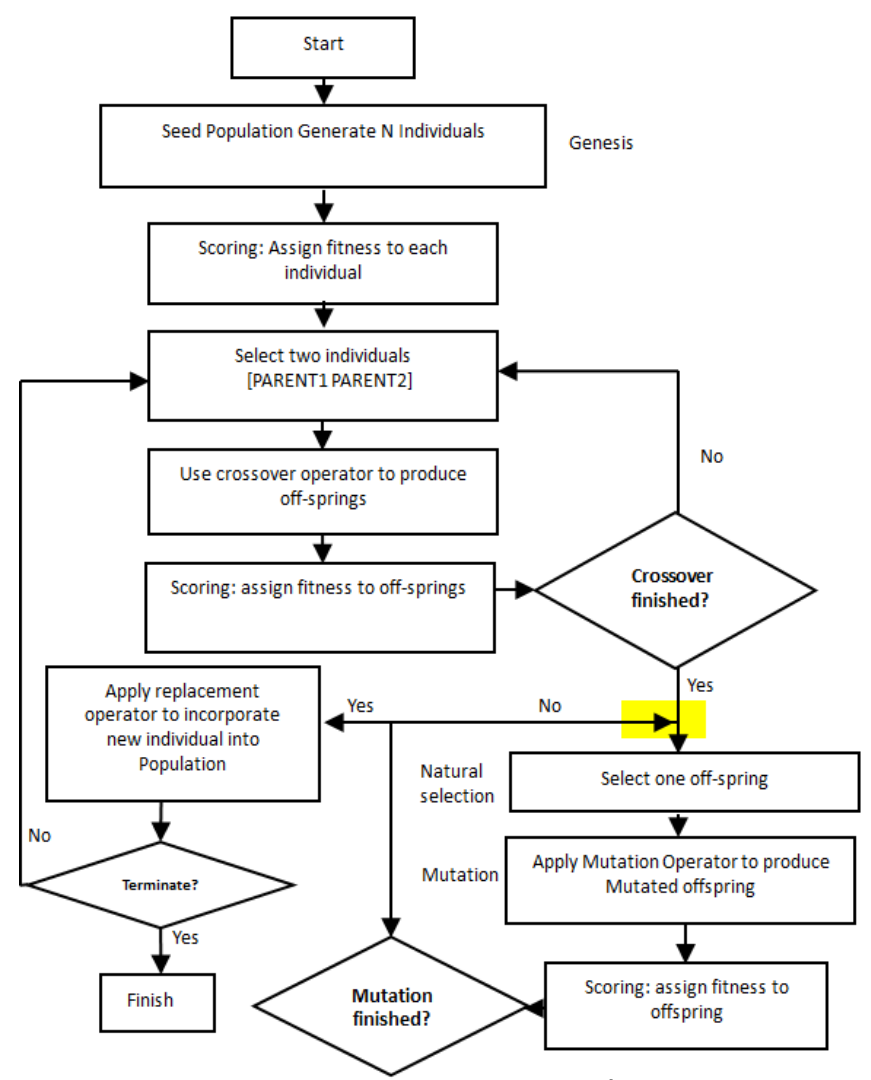

Figure 3. Flowchart for GA optimization. 


\section{Results and Discussion}

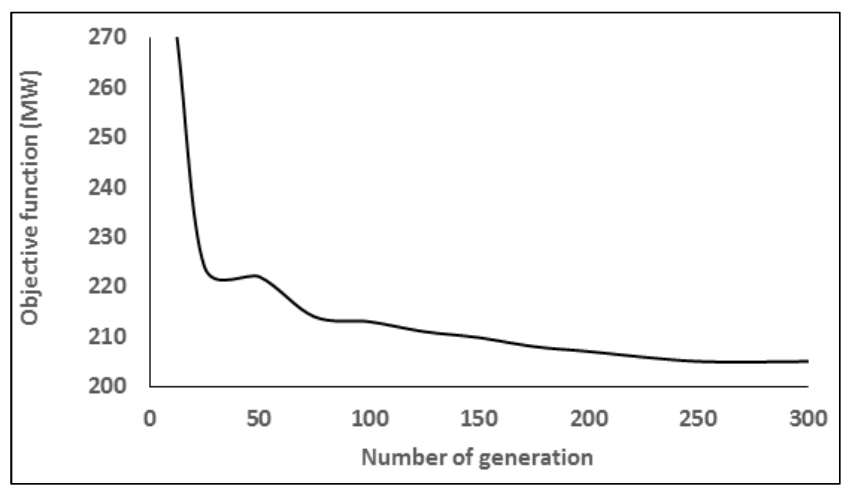

Figure 4. Variation of objective function with number of generation.

The variation of the objective function with the number of generations is shown in Figure 4.

The first 50 generations gave higher variation of the decision variables than the other generation numbers because searching in the first intervals were more sensitive. Thus, after about 70 generations, the objective function finds the real decision variables. From 150 generations, the change in the results obtained started giving relatively lower values under each iteration. The convergence (that is, no noticeable change in the value) of the objective function becomes obvious from 250 generations. However, the choice of 300 generations was to ensure that the search space was fully utilized without putting strain on the computation time and complexity [6], [5]. The ambient conditions were maintained at $303 \mathrm{~K}$ and $1.013 \mathrm{bar}$ because of location limitations. Several researchers [18], [19], [20], [21] have reported that ambient conditions have major impact on the plant's performance. Hence, various techniques have been proposed so far to enhance the thermal efficiency or power output of gas turbine power plant by reducing the compressor inlet air temperature [22], [23], [20]. These techniques include: evaporative cooling, fogging or with the help of absorption and mechanical chillers. However, the performance of evaporative media coolers is constrained in high relative humidity conditions such as that, encountered in Nigeria. And also, such coolers require de-mineralized water supply while electrically driven mechanical vapor-compression chillers consume significant amount of electrical power.

Table 4 shows the comparison between the base data and the optimum results of the decision variables.

Table 4. Comparison of the base data with the optimum result.

\begin{tabular}{llll}
\hline Property & Base data & $\begin{array}{l}\text { Optimum } \\
\text { result }\end{array}$ & $\begin{array}{l}\text { Variation } \\
(\%)\end{array}$ \\
\hline $\begin{array}{l}\text { Compressor pressure ratio, } r_{p} \\
\begin{array}{l}\text { Compressor isentropic } \\
\text { efficiency, } \eta_{i c}(\%)\end{array}\end{array}$ & 10.70 & 12.41 & 15.98 \\
$\begin{array}{l}\text { Turbine isentropic efficiency, } \\
\eta_{i t}(\%)\end{array}$ & 82.00 & 86.40 & 5.37 \\
$\begin{array}{l}\text { Turbine inlet temperature, } T_{3} \\
(K)\end{array}$ & $1,324.74$ & $1,486.36$ & 12.20 \\
\hline
\end{tabular}

\begin{tabular}{llll}
\hline Property & Base data & $\begin{array}{l}\text { Optimum } \\
\text { result }\end{array}$ & $\begin{array}{l}\text { Variation } \\
(\%)\end{array}$ \\
\hline $\begin{array}{l}\text { Mass flow rate of air, } \dot{m}_{a} \\
(\mathrm{~kg} / \mathrm{s})\end{array}$ & 427.00 & 355.82 & -16.67 \\
$\begin{array}{l}\text { Mass flow rate of fuel, } \dot{m}_{f} \\
(\mathrm{~kg} / \mathrm{s})\end{array}$ & 9.13 & 8.62 & -5.54 \\
\hline
\end{tabular}

As it is shown, the values of the variables $r_{p}, \eta_{i c}, \eta_{i t}$ and $T_{3}$ increased while $\dot{m}_{a}$ and $\dot{m}_{f}$ decreased. Increment of $r_{p}$ is by $15.98 \%, \eta_{i c}$ is by $5.37 \%, \eta_{i t}$ is by $4.85 \%$ while $T_{3}$ is by $12.20 \%$. Increased $r_{p}$ results in higher thermal efficiency whereas increased in $\eta_{i c}$ guarantees less exergy destruction in the compressor [2], [24], [25]. As gas turbine get older, its compressor airfoils tend to be rougher because of long exposure to the environment. Improving the performance of the compressor will impact positively on the performance of the gas turbine [3], [26]. Application of coatings to the compressor blades would be of help in improving its performance. Compressor blades coating provide smoother and more aerodynamic surfaces, which will lead to increased compressor efficiency. GECC- 1 coating combines the effects of an aluminum-coating to prevent corrosion and a ceramic top-coat to prevent erosion [27]. Corrosion and erosion are significant sources of performance degradation.

Increased $\eta_{i t}$ and $T_{3}$ play vital roles in decreasing the exergy destruction in the combustion chamber and in reducing cycle fuel consumption. Use of single-crystal material or use of the thermal barrier coatings are some material failure mitigation methods proposed for gas turbine using air, steam or water injection [27]. Since the gas turbine under investigation is over 25 years, thermal barrier coatings can be applied to the hot sections. These coatings will provide insulating barriers between the hot combustion gases and the metal parts [27], [3]. Thermal barrier coatings will increase the parts lifespan at the designed firing temperature or will allow an increased firing temperature while still maintaining the original designed lifespan of the hot section.

The reduction in $\dot{m}_{f}$ is by $5.54 \%$ while $\dot{m}_{a}$ is by $16.67 \%$. Reduced $\dot{m}_{a}$ and $\dot{m}_{f}$ contribute immensely to the reduction of total exergy destruction. Minimization of exergy destruction means maximization of the exergetic efficiency [28], [7], [5]. However, since mass flow rates ( $\dot{m}_{a}$ and $\dot{m}_{f}$ ) impact positively on increasing the objective function, the GA tends to optimally find decision variables which will result in decreased mass flowrates. Reduction in mass flowrates reduces emissions thereby decreasing the gas turbine's negative impact on the environment [29]. Any change in the numerical values of a decision variable not only affects the performance of the related equipment but also the performance of other equipment as well [24].

\section{Conclusion}

The optimization of the plant's operating parameters (decision variables) has been carried out using NSGA. The 
decision variables were randomly generated within the admissible range. The optimal values of the decision variables (constraints) were obtained by minimizing the objective function. The developed GA code selects the decision variables in such a way to decrease the objective function. The convergence of the objective function becomes obvious from 250 generations. However, the choice of 300 generations was to ensure that the search space was fully utilized without putting strain on the computation time and complexity. The ambient conditions were maintained at $303 \mathrm{~K}$ and $1.013 \mathrm{bar}$ because of location limitations.

Optimized values revealed that $r_{p}, \eta_{i c}, \eta_{i t}$ and $T_{3}$ were increased from their base values by $15.98 \%, 5.37 \%, 4.85 \%$ and $12.20 \%$ respectively while $\dot{m}_{a}$ and $\dot{m}_{f}$ were reduced from their base values by $16.67 \%$ and $5.54 \%$ respectively. Increased $r_{p}$ results in higher thermal efficiency whereas increased $\eta_{i c}$ guarantees less exergy destruction in the compressor. Suggested application of coatings to the compressor blades will increase the compressor efficiency. Increased $\eta_{i t}$ and $T_{3}$ contribute greatly to the reduction of exergy destruction in the combustion chamber as well as reduction in the cycle fuel consumption. Applying thermal barrier coatings to the hot sections of the gas turbine unit will increase the parts lifespan at the designed firing temperature or allow an increased firing temperature while still maintaining the original designed lifespan of the parts.

Reduced $\dot{m}_{a}$ and $\dot{m}_{f}$ contributed immensely to the reduction of the total exergy destruction. Less $\dot{m}_{a}$ and $\dot{m}_{f}$ directly imply less emissions from the plant and consequently reduction in the gas turbine's negative impact on the environment.

\section{References}

[1] Gorji-Bandpy, M. and Goodarzian, H. (2011); Exergoeconomic Optimization of Gas Turbine Operating Parameters using Genetic Algorithms: A Case Study, Thermal Science, Vol. 15, No. 6, pp. 129-136.

[2] Abam, F. I.; Ugot, I. U. and Igbong, D. I. (2012); Effect of Operating Variables on Exergetic Efficiency of an Active Gas Turbine Power Plant, Journal of Emerging Trends in Engineering and Applied Sciences, Vol. 3, No. 1, pp. 131-136.

[3] Oyedepo, S. O.; Fagbenle, R. O. and Adefila, S. S. (2017); Modelling and Assessment of Effect of Operating Parameters on Gas Turbine Power Plant Performance using First and Second Laws of Thermodynamics, American Journal of Engineering and Applied Sciences, DOI: 10.3844.

[4] Ighodaro, O. O. and Aburime, B. A. (2011); Exergetic Appraisal of Delta IV Power Station Ughelli, Journal of Engineering Trends in Engineering and Applied Sciences, Vol. 2, No. 2, pp. 216-218.

[5] Naserian, M. M.; Farahat, S. and Sarhaddi, F. (2016); Exergoeconomic Analysis and Genetic Algorithm Power Optimization of an Irreversible Regenerative Brayton Cycle, Energy Equipment and Systems, Vol. 4, No. 2, pp. 189-203.
[6] Khosravi, A.; Gorji-Bandpy, M. and Fazelpour, F. (2014); Optimization of a Gas Turbine Cycle by Genetic and PSO Algorithms, Journal of Middle East Applied Science and Technology (JMEAST), Issue 21, pp. 706-711.

[7] Gupta, M and Kumar, R. (2015). Optimization of an open cycle Gas Turbine Power Plant using Exergoeconomics. International Journal of Recent Advances in Mechanical Engineering, Vol. 4. No. 4, pp. 95-104.

[8] Javadi, M. A. and Ghomashi, H. (2016); Thermodynamics Analysis and Optimization of Abadan Combined Cycle Power Plant, Indian Journal of Science and Technology, Vol. 9, No. 7, pp. 60-72.

[9] Henry, E. O. and Albert, A. I. (2013); Exergetic Analysis of Omotosho Phase 1 Gas Thermal Power Plant, International Journal of Energy and Power Engineering, Vol. 2, No. 5, pp. 197-203.

[10] Husnain, N.; Khan, W. A.; Qureshi, S. R.; Siddiqui, F. A.; Wang, E. and Mehmood, A. (2017); Exergetic and Energetic Analysis of a 210 MW Thermal Power Plant in Pakistan, Technical Journal, University of Engineering and Technology (UET) Taxila, Pakistan, Vol. 1, pp. 66-77.

[11] Mitchell, M. (1999); An Introduction to Genetic Algorithms, First Paperback Edition, Fifth Printing, A Bradfort Book, The MIT Press, London, 158pp.

[12] Coley, A. D. (1999); An Introduction to Genetic Algorithms for Scientists and Engineers, $2^{\text {th }}$ Edition, World Scientific Publishing Co. Pte. Ltd, Singapore, 211pp.

[13] Malhotra, R.; Singh, N. and Singh, Y. (2011); Genetic Algorithms: Concepts, Design for Optimization of Process Controllers, Computer and Information Science, Vol. 4, No. 2, pp. 39-54.

[14] PHCN (2015); Ughelli Power Plant Logbook, Ughelli, Delta State, Nigeria.

[15] Obodeh, O. and Ugwuoke, P. E. (2013); Time-Dependent Exergy Analysis of a 120 MW Steam Turbine Unit of Sapele Power Plant, American Journal of Electrical Power and Energy Systems, Vol. 2, No. 6, pp. 129-136.

[16] Acur, A.; Bilginsoy, A. K. and Cos, K. H. (2012); Investigation of varying Dead State Temperatures on Energy and exergy Efficiencies in Thermal Power Plant, Journal of the Energy Institute, Vol. 85, No. 1, pp. 14-21.

[17] Srinivas, N. and Deb, K. (2002); Multi-Objective Optimization using Non-Dominated Sorting in Genetic Algorithms, Journal of Evolutional Computation, Vol. 2, No. 3, pp. 221-248.

[18] Farouk, N.; Sheng, L. and Hayat, Q. (2013); Effect of Ambient Temperature on the Performance of Gas Turbine Power Plant, International Journal of Computer Science Issues, Vol. 10, Issue 1, No. 3, pp. 439-442.

[19] Gopinath, V. and Navaneethatkrishnan, G. (2013); Performance Evaluation of Gas Turbine by Reducing the Inlet Air Temperature, International Journal of Technology Enhancements and Emerging Engineering Research, Vol. 1, pp. 2347-2353.

[20] Mohapatra, A. K. and Nit, S. S. (2015); Comparative Analysis of Inlet Cooling Techniques Integrated to Cooled Gas Turbine Plant, Journal of Energy Institute, Vol. 88, pp. 344-358. 
[21] Ibrahim, T. K.; Rahman, M. M.; Ali, O. M.; Basrawi, F. and Mamat, R. (2016); Optimum Performance Enhancing Strategies of the Gas Turbine based on Effective Temperatures, MATEC Web of Conferences 38, DOI: $10.1051 /$ matecconf/20163801002.

[22] Popli, S.; Rodgers, P. and Eveloy, V. (2013); Gas Turbine Efficiency Enhancement using Waste Heat Powered Absorption Chillers in the Oil and Gas Industry, Applied Thermal Engineering, Vol. 1, pp. 918-931.

[23] Alam, S. H.; Sasso, T. and Djunaedi, I. (2015); Performance Enhancement of Gas Turbine Power Plant via Wet Compression Technique and Its Effects on Economic Aspects, British Journal of Applied Science and Technology, Vol. 11, No. 1, pp. 1-12.

[24] Ghaderi, R. and Damircheli, M. (2014); Investigating Factors Affecting the Efficiency of Gas Turbine Power Cycle, Scientific Journal of Pure and Applied Sciences, Vol. 3, No. 5, pp. 217-279.

[25] Ogbe, P. O.; Anosike, N. B. and Okonkwo, U. C. (2016); Exergoeconomic Evaluation of Transcorp Power Plant
Ughelli, International Research Journal of Engineering and Technology, Vol. 3, Issue 11, pp. 36-44.

[26] Sharma, A. K.; Singhania, A.; Kumar, A.; Roy, R. and Mandal, B. K. (2017); Improvement of Gas Turbine Power Plant Performance: A Review, International Journal of Innovative Research in Engineering and Management; Vol. 4, Issue 3, pp. 658-663.

[27] Janawitz, J.; Masso, J. and Childs, C. (2015); Heavy-Duty Gas Turbine Operating and Maintenance Consideration Ger 3620M, GE Power and Water, Atlanta, Georgi, 48pp.

[28] Igbong, D. I. and Fakorede, D. O. (2014); Exergoeconomic Analysis of 100 MW Unit GE Frame 9 Gas Turbine Plant at Ughelli, Nigeria, International Journal of Engineering and Technology, Vol. 4, No. 8, pp. 463-468.

[29] Memon, A. G.; Harijan, K.; Uqaili, M. A. and Memon, R. A. (2013); Thermo-Environment and Economic Analysis of Simple and Regenerative Gas Turbine Cycles with Regression Modelling and Optimization, Energy Conversion Management, Vol. 76, pp. 852-864. 